\title{
ATUALIZAÇÃO
}

\section{DOENÇAS TROPICAIS E O DESENVOLVIMENTO}

\section{DA AMAZÔNIA ${ }^{1}$}

Wilson Duarte Alecrim ${ }^{2}$

\section{RESUMO}

A Amazônia é uma região compartilhada por vários países, no entanto, a sua maior parte está em território brasileiro. Nas últimas décadas ocorreram grandes correntes migratórias que determinaram profundas alterações na nosologia dessa região. Um processo migratório ocorreu durante a segunda guerra mundial com a finalidade de produzir borracha (látex) e o mais recente verificou-se a partir de 1975 quando o governo federal planejou uma ampla ocupação da amazônia para aumentar a produção no setor primário. As doenças endêmicas, principalmente malária e leishmaniose, agravaram epidemiologicamente nessas ocasiões. $\mathrm{O}$ desenvolvimento cientifico e tecnológico da amazônia, nas últimas quatro décadas vem sendo propiciado pelas instituições como Universidades e Institutos instalados na própria região, constituindo-se hoje em importante massa critica, permitindo estudos de forma continuada e sistematizada, embora ainda não suficientes para as necessidades requeridas.

UNITERMOS: Amazônia. Doenças tropicais.

A Amazônia representa uma das últimas fronteiras onde existem as condições que podem se comportar como favoráveis para a qualidade de vida no mundo, representadas por um conjunto de ecossistemas. É uma região compartilhada por vários países, sendo a sua maior parte ainda de domínio geográfico e político do Brasil. Pode ser considerada uma região ímpar no mundo devido às suas características físicas e culturais e à grande biodiversidade. Difere de regiões não iguais, mas assemelhadas em vários aspectos principalmente na Ásia e África. Gostaríamos de lembrar um ponto que pode ser considerado de grande importância, qual seja a ocupação dos

1 Conferência de abertura da V Jornada de Diagnóstico, Tratamento e Controle de Doenças Tropicais, Santarém - Pará, 23 a 28 de julho de 2001.

2 Diretor-Presidente da Fundação de Medicina Tropical, Instituto Medicina Tropical - Manaus AM. Diretor da Escola Superior de Ciências da Saúde, Universidade do Estado do Amazonas e Professor da Universidade Federal do Amazonas.

Endereço para correspondência: e-mail: imtam@prodamnet.com.br ou alecrim@uol.com.br

Recebido para publicação em 29/7/2001. 
espaços, pois enquanto nos outros continentes essas áreas apresentam densidade demográfica superior a 15 habitantes por quilômetro quadrado, aqui esse número cai para 4. A Amazônia brasileira, com sua área de 5.109 .000 quilômetros quadrados, está habitada por não mais que 18 milhões de pessoas, representando $59 \%$ do território nacional e $10,7 \%$ da população.

Ao falarmos sobre desenvolvimento para a Amazônia e na Amazônia, podemos fazer profundas reflexões, e assim inferir que esse desenvolvimento deve guardar relação direta com a melhoria da qualidade de vida das populações. Na lógica capitalista, se assim podemos dizer, o desenvolvimento está vinculado ao processo de difusão do progresso técnico, determinado pelo interesse da economia criadora de novas técnicas, o que resulta na produtividade. $\mathrm{O}$ desenvolvimento apenas calcado na produtividade e no lucro resulta numa forte concentração de renda, o que para alguns é aceitável, uma vez que essa concentração permite mais oferta de empregos. No entanto, é importante mencionar que toda concentração de renda está intimamente ligada à pobreza, e são inúmeros os trabalhos confirmando que a massa de pobreza encontrada em determinada economia é resultado direto do defeituoso crescimento da produtividade. Portanto, sob o ponto de vista social, devemos encontrar um caminho onde o desenvolvimento promova a melhoria da qualidade de vida, permitindo no mínimo uma alimentação saudável e qualitativa, habitação com condições de saneamento básico, acesso à educação, ao lazer e às atividades culturais.

As chamadas doenças endêmicas guardam profunda relação entre o meio ambiente e o ser humano. Historicamente essas doenças aparecem como entrave ao desenvolvimento; o exemplo que marca essa assertiva na Amazônia é a construção da estrada de ferro Madeira-Mamoré, que ficou conhecida como a ferrovia do diabo. No período que foi de 1872 a 1912, a malária ceifou vida de trabalhadores e fez com que o cronograma físico fosse alterado por várias vezes, incluindo mudanças de empresas construtoras.

A idéia de ocupar os espaços e desenvolver a Amazônia produziu fluxos migratórios para essa região, e foram vários, mas dois merecem ser lembrados. Durante a Segunda Guerra Mundial, para aumentar a produção da borracha natural, tivemos uma grande corrente migratória do Nordeste para a Amazônia, onde mais uma vez as doenças produziram sua marca, e aqui transcrevemos um trecho de uma das obras de Samuel Pessoa:

Deve-se notar que, na última campanha da borracha durante a Segunda Guerra (batalha da borracha), milhares de nordestinos encaminhados pelas repartições oficiais pereceram tragicamente nas florestas amazônicas. Não se sabe ao certo o número, porém Alfredo Pinheiro (1946) calcula que, dos milhares de homens encaminhados, cerca de 55.000 tiveram morte trágica, abandonados no vale amazônico e vitimados pela fome e doenças endêmicas. 
Nas décadas mais recentes, a partir de 1970, o governo federal começa mais uma tentativa de ocupação (desenvolvimento) da Amazônia, trabalhando em projetos de integração rodoviária (Transamazônica e Perimetral Norte), construção de hidrelétricas e projetos de assentamentos. Com a instalação de agrovilas, a Amazônia estava sendo planejada para ser a mais nova fronteira agrícola do País, e, como não poderia deixar de ser, grande parte do que foi planejado ficou pela metade, a ponto de a Transamazônica ser considerada não como uma rodovia, mas como um caminho abandonado no meio da floresta. Nessa ocasião aconteceu nova corrente migratória, dessa vez não só a partir do Nordeste; também vieram para a Amazônia brasileiros do Leste e Sul. Quais os principais fatores considerados atrativos para essa migração? Foram vários, no entanto, dois podem ser caracterizados: terra para produção no setor primário e garimpo de ouro. É importante mencionar que esses fatores tiveram como motivos o desemprego nas áreas rural e urbana do Leste e Sul. Na área rural, o desemprego foi produzido pela mudança na economia, quando ocorreu a substituição do cultivo de café por soja, em que a mão-de-obra também foi substituída pela mecanização. Na área urbana, também ocorreu a automação dos parques industriais. Esta última corrente migratória, assim, deve ter contribuído para a malária passar de 64 mil casos em 1974 para 632 mil em 1999.

As doenças tropicais na Amazônia apresentam poucas especificidades na sua etiologia, e não são muitas as doenças próprias ou específicas dessa região. No geral, a dinâmica representada pelo aumento do número de pessoas adoecendo guarda relação direta com o papel que o ser humano desenvolve e está na dependência do estabelecimento de uma relação defeituosa entre o homem e os ecossistemas. Apesar dos esforços desenvolvidos no sentido de controlar ou erradicar as doenças transmissíveis e tropicais na Amazônia brasileira, não tem sido possível conseguir êxito ou resultados satisfatórios em todas essas doenças. Assim, podemos dizer que aquelas para as quais existem vacinas eficazes e disponíveis nos programas de saúde pública, como tétano, difteria, coqueluche e sarampo, ocorreu marcada redução no número de casos. A poliomielite, por exemplo, está erradicada. Dentre as chamadas endemias, isso também ocorre com febre amarela, em que só temos a forma silvestre. $\mathrm{O}$ mesmo não é possivel referir para as endemias ou doenças transmissíveis, para as quais não existem vacinas ou essas vacinas são de baixa proteção.

As nossas condições ecológicas são extremamente favoráveis para a manutenção ou elevação da transmissão de doenças endêmicas, principalmente aquelas que possuem mosquitos como vetores. A idéia de relacionar as doenças com o meio ambiente já vem desde Hipócrates e pode ser encontrada no primeiro Tratado de Geografia Médica denominado "Ares, Água e Lugares", em que se ressaltam como elementos que atuam sobre o 
homem a água, a terra, o fogo e o ar, e se adverte: quem quiser investigar devidamente a medicina deve considerar as estações do ano e os efeitos que elas exercem, os ventos, a água, o sol, o solo e as atividades de seus habitantes. No entanto, a idéia de que as doenças se distribuem diferentemente, segundo as regiões, aparece com Boundin em 1857 na obra Traité de Geographie et de Statistique Medicales et des Maladies endemiques, ao afirmar que o homem não nasce, vive, sofre e morre de maneira idêntica nas várias partes do mundo, ou seja, a concepção, o nascimento, a vida, a doença e a morte variam com o clima, o solo, as estações do ano, os meses, a raça e até com a nacionalidade. Essas afirmações praticamente dominaram o entendimento sobre a origem das doenças até a primeira metade do século XIX.

A princípio, poderiamos pensar que a Amazônia é uma região homogênea geograficamente. No entanto, essa homogeneidade é apenas aparente, visto que existem diferenças e, embora não sejam de grande monta, podem servir para mudar o ecossistema. No Estado do Amazonas, uma imensa planície de 1.550 mil quilômetros quadrados de área, não existe a Lutzomia longipalpis, mas esse mosquito pode ser encontrado mais ao norte e mais ao sul da Amazônia brasileira. Da mesma forma, podemos aceitar que na Amazônia como um todo temos diversidades étnicas e culturais. Um conceito com o qual devemos trabalhar é que, embora possamos encontrar diversidades dentro da Amazônia, essa região possui características próprias que a fazem diferente das outras partes do mundo, e por essa razão dever ser estimulada a busca do conhecimento, fortalecendo as instituições existentes com a finalidade do desenvolvimento científico e tecnológico para melhoria da qualidade de vida dos amazônidas.

Um dos entraves ao desenvolvimento da Amazônia é representado pelas doenças que ainda são de elevada incidência nessa região. $\mathrm{Na}$ Amazônia brasileira a malária se apresenta como um dos principais e mais importantes problemas de saúde. Em 1974 o registro de casos foi de 64.320, no entanto, a partir de 1975 verificamos um aumento progressivo da doença, que em 1988 já ultrapassava a cifra dos 500.000 casos/ano. Durante o ano de 1998 foram registrados $469.980 \mathrm{e}$, em 1999, 631.000. Vale ressaltar, atualmente, $99,8 \%$ da malária do Brasil ocorre na Amazônia. O seu aumento guarda relação com muitos fatores, quase sempre representados pelos projetos de desenvolvimento, problemas de recursos para o controle, pela mudança no comportamento do vetor Anopheles darlingi diante dos inseticidas e pela resposta dos plasmódios aos antimaláricos. O Programa brasileiro está fazendo um grande esforço para a implantação da estratégia do controle global e integrado, com a descentralização e o envolvimento de toda a rede e de todos os serviços de saúde, com modesta redução durante o ano 2000 e, durante os seis primeiros meses de 2001, principalmente nos Estados do Acre e Amazonas, com redução de $70 \%$. O Ministério da Saúde trabalha 
com a expectativa de que os 631 mil casos de 1999 sejam reduzidos para 315 mil em 2001. A febre amarela até a década de 1940 representava grande e importante problema, tanto nas áreas urbanas como rurais. Nos últimos anos a doença vem ocorrendo no Brasil com grande concentração na Amazônia, e nessa região apenas na área rural, embora exista considerável risco de urbanização, devido à reinfestação das áreas urbanas pelo Aedes aegypti. Dos nove Estados, quatro - Amazonas, Pará, Rondônia e Maranhão - são responsáveis por $97,04 \%$. A ocorrência de febre amarela ainda se deve à nãocobertura vacinal satisfatória, uma vez que o Brasil fabrica uma vacina de ótima qualidade, e uma única dose é capaz de proteger a quase totalidade dos vacinados por 10 anos.

Em 1981 - 1982 tivemos uma epidemia de dengue em Roraima, no sul da Amazônia, com a estimativa de 10 mil casos, que ficou restrita àquela área. Posteriormente, somente no ano de 1994, após 14 anos, voltamos a registrar dengue na Amazônia, embora o Aedes aegypti já estivesse em algumas áreas urbanas desde muito tempo. No período que vai de 1994 a outubro de 1999 foram registrados 139.092 casos de dengue confirmados sorologicamente, com a presença dos sorotipos 1 e 2. Os Estados do Amazonas, Maranhão, Mato Grosso e Pará foram os mais atingidos e são responsáveis por $90,57 \%$ dos casos. Os casos de febre hemorrágica do dengue (FHD) são de pouco registro na região, embora tenha sido registrada uma epidemia de FHD em Manaus, com 56 casos durante o primeiro trimestre de 2001.

A Leishmaniose Tegumentar Americana constitui importante problema de saúde na Amazônia brasileira, com uma média anual de 17.450 casos. No período de 1990 a setembro de 1999 foram notificados no Brasil 274.517 casos; desses, 165.121 (94,8\%) aconteceram na Amazônia. Embora não seja importante na mortalidade, sua morbidade, a possibilidade do aparecimento de formas graves ou mutilantes, bem como a dificuldade no tratamento são fatores que devem ser considerados em relação a essa endemia. Vários mosquitos do gênero Lutzomia estão envolvidos na transmissão, e diversas espécies de Leishmania na determinação da doença, possibilitando um modelo epidemiológico diversificado e a manifestação também variada nas formas clínicas.

Leishmaniose visceral, ou Calazar, tem registro em apenas 4 dos 9 Estados da Amazônia, com um total de 3.512 casos nos últimos 10 anos, dos 4 Estados: Tocantins, Roraima, Pará e Maranhão; o último é responsável por $72,69 \%$ das notificações.

Dos casos de hanseníase registrados no Brasil, $40 \%$ acontecem na Amazônia. É uma doença cuja prevalência está em declínio, no entanto a detecção de casos não apresentou significativa variação para diminuição. Nos últimos 3 anos foram detectados 46.725 casos novos com um média de $15.575 / a n o$ e $42,6 /$ dia. É uma situação preocupante, em razão dos problemas 
médicos e sociais que a doença determina, e também porque trabalhávamos com a meta de eliminação da doença até o ano 2000. Em 1997, na detecção de casos temos 8,89 por 100 mil habitantes e na prevalência encontramos 15,48 . Esses indicadores ainda podem ser considerados elevados. Atualmente o programa está em fase de avaliação e possivelmente novas recomendações e orientações serão incorporadas.

A notificação dos casos de tuberculose na Amazônia não representa o mesmo perfil do Brasil. No País temos um aumento no número de casos, enquanto na Amazônia verificamos que no período de 1994 a 1998 não ocorreu modificação para maior (a média anual é de 11.131 casos novos, com 56,6 por 100.000 habitantes).

A epidemia de Aids que se espalha pelo mundo fez seus primeiros casos na Amazônia em 1986. No período de 1986 a 1998 já foram registrados 5.132 casos de Aids com 26,8 por 100.000 habitantes. Os casos da Amazônia correspondem a 8,8\% dos registrados no Brasil. Em 1997 e 1998 verificamos diminuição no número de casos diagnosticados na Amazônia, que pode ser considerada como resultado dos elevados recursos que estão sendo destinados para controle da doença e atenção aos doentes. Existe na Região um amplo programa com recursos públicos que possibilita facilidades para diagnóstico, tratamento e profilaxia.

No Brasil o primeiro caso de oncocercose foi descrito no ano de 1967 em Roraima, acometendo a filha de um missionário que trabalhava naquela região. Nos anos seguintes a doença foi descrita no Amazonas, e está praticamente restrita ao Parque Indígena Yanomami no norte de Roraima e Amazonas. O programa brasileiro de controle da oncocercose usa como principal estratégia o tratamento dos que apresentam a microfilária. $\mathrm{O}$ controle do vetor, devido às dificuldades operacionais na área da doença, não vem sendo trabalhado.

A doença de Chagas na Amazônia brasileira pode ser considerada como de ocorrência ocasional. Os casos agudos ou crônicos estão em torno de 238. Um dos fatores que contribuem para essa situação epidemiológica é que os vetores não se tornaram domésticos na Amazônia; eles existem, principalmente Panstrongylus e Rhodnius; também o T. cruzi tem sido encontrado em vários animais silvestres.

É impossivel e inaceitável falar em Amazônia e não fazermos referência aos povos indígenas. Dessa forma, a população indígena brasileira é estimada em cerca de 320 mil pessoas, das quais 50\% vivem na Amazônia. Estão agrupados em 206 etnias e ocupam 554 territórios indígenas. Nos Estados do Amazonas e Roraima está a maior parte dos índios que vivem na Amazônia. As condições de saúde de uma população são reflexos das situações políticas e econômicas, mas sempre estão fortemente relacionadas com aspectos culturais. Os povos indígenas, na sua maioria, apresentam precárias condições de saúde, quase sempre decorrentes das alterações que a 
exploração predatória determina nos seus territórios, levando em muitas vezes à perda da identidade cultural. As causas que levaram à drástica redução das populações indígenas são várias, e não podemos deixar de incluir as doenças, até mesmo pela forma epidêmica como elas ocorreram. Essas epidemias estavam relacionadas principalmente com baixa imunidade daquelas populações e dificuldades de acesso aos serviços de saúde, tanto para proteção como para atenção aos doentes. Infecções respiratórias agudas, diarréias, sarampo, tuberculose, malária e desnutrição são as mais freqüentes, embora não sejam as únicas. As mudanças no estilo de vida levam ao aumento do alcoolismo e violência. Os Yanomami apresentam como primeira causa de morbidade a malária. As populações indígenas são realmente mais suscetíveis às doenças devido à sua composição biológica, portanto o impacto da assistência primária à saúde pode ser inferior ao esperado. A miscigenação tem sido apontada como um fator que pode estar atuando positivamente na capacidade de resposta imunológica. Os Kayapó nas últimas décadas apresentaram significativo aumento populacional, que pode estar associado ao fato da heterogeneidade genética resultante de casamentos com mulheres de outras tribos. Assim a homogeneidade genética após o contato deve exercer uma influência negativa na capacidade de responder às doenças introduzidas.

No Brasil, as Conferências Nacionais de Saúde do Índio recomendaram a estruturação de um modelo de atenção, com responsabilidade federal, baseado em Distritos Sanitários Especiais Indígenas, como forma de garantir seu direito universal e integral à saúde, respeitando suas especificidades socioculturais e os sistemas tradicionais de saúde. Essas recomendações vinham sendo executadas pela Funai, órgão que cuida da política indígena no País. Em julho de 1999 a responsabilidade pela saúde indígena passou para o Ministério da Saúde, através da Fundação Nacional de Saúde/Funasa, cujos resultados iniciais mostram melhoria na atenção à saúde dos povos indígenas.

Os povos indígenas, ao longo dos anos após o contato, perdem grande parte da capacidade de realizar suas atividades na área de saúde, que certamente não seriam suficientes para atender a uma nova realidade de necessidades. Essa realidade é decorrente de vários fatores, principalmente as alterações no meio ambiente, colocando-os aos riscos de vetores ou veiculadores de doenças e a experimentar, no organismo, agentes etiológicos até então nunca experimentados. É uma condição de fragilização social e cultural com sérias e graves conseqüências. É necessário analisarmos até que ponto a nossa prática médica, na forma como a empregamos, é pelos índios assimilada ou aceita. Muitas são as informações sobre as dificuldades para completar o tratamento de algumas doenças como malária e tuberculose.

É importante abordarmos a produção do conhecimento na Amazônia, lembrando que durante muito tempo essa produção teve como 
origem as observações realizadas pelas "expedições exploradoras", num primeiro momento feitas pelos europeus, a seguir por norte-americanos e mais recentemente pelos brasileiros do Leste e do Sul. Na realidade, todos partiam com a idéia de desvendar os mistérios da Amazônia e não raro produziam informações fragmentadas e pontuais, que em muitas ocasiões permitiram o emprego de estigmas como chamar a região de "inferno verde" e ultimamente de "inferno sanitário". Coube ao naturalista Alexandre Rodrigues Ferreira, em 1783, a primeira tentativa de revelação científica do vale amazônico, ao realizar um trabalho para a Corte portuguesa, produzindo um vasto material que se estendia da etnografia à zoologia. Nos últimos cinqüenta anos, uma considerável infra-estrutura técnica e científica tem sido instalada na Amazônia. São universidades e institutos de pesquisa que continuadamente estão trabalhando e não eventualmente, como no caso das excursões; estas últimas são importantes, mas tendem a representar uma informação pontual. A Amazônia de hoje, no tocante à sua base científica, apresenta profundas diferenças do que havia no passado, mais em função das instituições e dos brasileiros que hoje aqui estão estudando, trabalhando, e menos devido a uma política nacional para a Amazônia. A palavra de ordem mundial na produção científica chama-se parceria, portanto é inadmissível que ainda nos dias atuais continuemos assistindo a procedimentos na Amazônia que desconsideram a capacidade instalada existente, ou ainda procedendo como se a busca do conhecimento científico fosse apanágio apenas de alguns, ainda em um cenário de pouca parceria, que no nosso entendimento é devido à lógica com a qual as instituições das outras regiões trabalham, ou seja, não fazem um diagnóstico correto, desconsiderando a capacidade instalada na Amazônia e permitindo-se desenvolver ações paralelas.

Um olhar sobre os acontecimentos em relação à Amazônia nos remete para algumas interpretações que foram modificadas temporalmente. Durante as décadas de 1940 e 1950 o movimento destinado à internacionalização da Amazônia apresentava motivos diferentes do que hoje observamos. Naquela altura o grande interesse estava na riqueza do nosso subsolo, principalmente os minérios; atualmente os motivos principais são a água doce e a riqueza da nossa biodiversidade. $\mathrm{O}$ Brasil não pode e não deve continuar olhando a Amazônia como um problema. Talvez os estrangeiros a olhem como solução para os problemas em relação à qualidade de vida e ao desenvolvimento econômico, razão pela qual continuadamente essa região está em discussão, em que pese o questionamento sobre o direito que os países têm de continuar com a soberania sobre a região. Não está difícil perceber que dois argumentos, narcotráfico e condição de monitoramento ecológico, estão sendo usados pelos países do chamado primeiro mundo para justificar a chamada soberania relativa da região. As manifestações dos políticos e pesquisadores daqueles países são as de que se somos incapazes e 
incompetentes para controlar o narcotráfico e evitar grandes desastres ecológicos, e que, portanto, teríamos que admitir a tese da internacionalização. $\mathrm{Na}$ realidade, o que podemos verificar é um nãoconfessável interesse na nossa água doce e biodiversidade.

A Amazônia com sua imensa biodiversidade continua sendo um desafio à inteligência de pesquisadores e políticos no sentido de estabelecerem mecanismos que possibilitem o desenvolvimento e a melhoria da qualidade de vida sem o estabelecimento de confronto com a natureza.

Voltamos a afirmar que a Amazônia representa para o mundo uma das mais importantes áreas no que diz respeito à melhoria das condições de vida e equilibrio ambiental. Partindo dessa premissa, qualquer ação realizada nessa região está intimamente vinculada com a saúde das populações. É uma região formada por vários ecossistemas, que determinam algumas de suas mais importantes características e peculiaridades, tornando-a ímpar no mundo.

As ações de saúde na Amazônia devem estar voltadas para dar atenção (assistência) aos agravos existentes e conhecidos, como também contemplar a pesquisa para suprir duas lacunas importantes, a saber: identificar doenças ainda não conhecidas e desenvolver tecnologias para o controle de todas as formas de agravos à saúde humana. Um forte investimento no campo das doenças tropicais e infecciosas, emergentes e reemergentes, sem o qual não será possível pensar no desenvolvimento da região, é obrigação e dever de todas as instituições nacionais. Nos Estados Unidos e na Alemanha o estudo das doenças tropicais é uma estratégia militar. Para os primeiros amplia a sua força intervencionista, e para a Alemanha contribui nas forças da paz.

O desenvolvimento da Amazônia não pode e não deve ser trabalhado de uma forma qualquer. Algumas vezes, programas desenvolvimentistas de outras regiões determinam o aparecimento ou aumento dos problemas existentes. Devemos aqui recordar que a malária constitui nas últimas décadas o mais importante problema de saúde pública na região, chegando a 631 mil casos em 1999; no entanto, em 1974, o registro de casos era de 62 mil. O aumento dessa importante endemia guarda relação direta com a política adotada para o setor primário no Sul e Leste durante a década de 1970, quando o Brasil adotou a substituição do cultivo e da produção do café pela soja, deixando milhares de trabalhadores desempregados no meio rural. Na tentativa de resolver esse grave problema social, no Leste e no Sul, o governo iniciou uma série de grandes projetos na Amazônia. Milhares de brasileiros vieram para a Amazônia, que não foi devidamente preparada para suportar a demanda. As pessoas ocuparam os espaços onde era grande a vulnerabilidade para a transmissão da malária, e chegando apresentavam considerável susceptibilidade, resultando no problema do tamanho que hoje se configura. Tivemos assim o agravamento 
de um problema na Amazônia, devido a uma mudança na produção agrícola e econômica em outras regiões do País.

Finalizando, reafirmamos a necessidade de que quando planejarmos algo para a Amazônia levemos em consideração alguns pontos que são importantes para resultar no produto esperado, nunca desconsiderando a sua potencialidade e os prejuízos advindos pela manipulação inadequada da natureza.

\section{ABSTRACT}

Tropical diseases and the development of Amazon

The Amazon is a region shared by some countries, however its major area is within brazilian territory. In the last decades migratory movements led to deep transformations in the region. One of the migratory processes occurred during Second World War in order to obtain latex, and the most recent was verified in 1975 when the Federal Government planned a wide occupation of the Amazon to increase the production in the primary sector. As a consequence, an increase on malaria and leishmaniasis was observed. Universities and institutes established in the region contributed to the scientific and technologic development of the Amazon in the last four decades with sistematic and continued studies. Nevertheless, much more should be done in order to fill up the needs of this region.

KEYWORDS: Amazon. Tropical diseases. 